Geopolítica(s) Revista de estudios sobre espacio y poder

ISSN: 2172-3958

\title{
Los pensamientos del indio que se educó dentro de las selvas colombianas y La bola que rodó en el desierto ${ }^{1}$
}

\author{
Manuel Quintín Lame
}

Resumen. Manuel Quintín Lame fue el líder indígena colombiano más importante del siglo XX. Nació en 1883 y creció como un siervo de la gleba en una hacienda localizada en los alrededores de Popayán, centro económico y político de la otrora sociedad de amos y hacendados de la provincia del mismo nombre, lideró el primer movimiento de indios contra las relaciones de terraje, una forma de la servidumbre, y por la recuperación de las tierras comunales o resguardos, como se les conoce en Colombia. Construyó un pensamiento político, largamente silenciado. La "Quintiada", como la forma superior de la resistencia a la disolución de la identidad cultural de los indios y sus ideales políticos son los precursores del movimiento indígena colombiano y latinoamericano contemporáneo.

Palabras clave: Colombia; Quintín Lame; "Quintiada"; movimiento indígena; resistencia; pensamiento político.

\section{[en] The Thoughts of the Indian who Was Educated in the Colombian Jungles and The Ball that Rolled in the Desert}

\begin{abstract}
Manuel Quintín Lame was the most important Colombian indigenous leader of the 20th century. He was born in 1883 and grew up as a serf in an hacienda located in the surroundings of Popayán, the economic and political centre in the former society of masters and landowners of the province of the same name. He led the first movement of Indians against the land relations, a form of servitude, and for the recovery of communal lands or resguardos, as they are known in Colombia. He developed a long-silenced political thought. The "Quintiada", as the highest form of resistance to the dissolution of the cultural identity of the Indians, and their political ideals, are the precursors of the contemporary Colombian and Latin American indigenous movement.
\end{abstract}

Keywords: Colombia; Quintín Lame; "Quintiada"; indigenous movement; resistance; political thought.

1 [Nota de la redacción] Se incluyen en esta selección los capítulos 1, 3, 5 y 7 del Libro Primero de "Los pensamientos del indio que se educó dentro de las selvas colombianas", dictado por Manuel Quintín Lame a Florentino Moreno, su secretario, entre los años 1910 y 1939, e incluido en el libro En defensa de mi raza (Bogotá: Comité de Defensa del Indio, 1971), publicado con introducción y edición de Gonzalo Castillo Cárdenas. La segunda parte de la selección está formada por "La bola que rodó en el desierto", escrito originalmente por Manuel Quintín Lame el 1 de mayo de 1963, y que fue publicado en el libro compilado por Gonzalo Castillo Las luchas del indio que bajó de las montañas al valle de la “civilización” (Bogotá: Rosca de investigación y acción social / Editextos, 1973). Se ha respetado la integridad y estructura de los textos originales, tal como Quintín Lame los escribió, siguiendo las transcripciones de Gonzalo Castillo (esto incluye respetar una ortografía anticuada y los errores que pueda haber en las transcripciones). 
[pt] Os pensamentos do índio educado nas selvas colombianas e A bola que rolou no deserto

Resumo. Manuel Quintín Lame foi o líder indígena colombiano mais importante do século XX. Ele nasceu em 1883 e cresceu como servo da gleba em uma fazenda localizada nos arredores de Popayán, o centro econômico e político da província de mesmo nome, outrora uma sociedade de senhores e latifundiários. Liderou o primeiro movimento dos índios contra as relações de terraje, uma forma de servidão, e pela recuperação das terras comunais ou resguardos, como são conhecidas na Colômbia. Ele construiu um pensamento político que foi longamente silenciado. A "Quintiada", como a forma principal de resistência à dissolução da identidade cultural dos índios e de seus ideais políticos, é uma precursora do movimento indígena contemporâneo colombiano e latino-americano.

Palavras-chave: Colômbia; Quintín Lame; "Quintiada"; movimento indígena; resistência; pensamento político.

Sumario. 1. Los pensamientos del indio que se educó dentro de las selvas colombianas. 1.1. El hombre indígena que recibe lecciones de la Naturaleza. 1.2. La virtud del indígena nacido y acariciado por la Naturaleza debajo de la madre selva. 1.3. La experiencia. 1.4. La sesión jurídica. 2. La bola que rodó en el desierto. 2.1. El contrabando antijurídico. 2.2. La civilización montés.

Cómo citar: Lame, M. Q. (2020). Los pensamientos del indio que se educó dentro de las selvas colombianas y La bola que rodó en el desierto. Geopolítica(s). Revista de estudios sobre espacio y poder, 12(1), 145-157. http://dx.doi.org/10.5209/geop.74676

\section{Los pensamientos del indio que se educó dentro de las selvas colombianas}

\subsection{El hombre indígena que recibe lecciones de la Naturaleza}

Allá en el bosque y no ha recibido compendios de estudios de los más recientes y renombrados pensadores, hombres que han recibido educaciones magistrales y clásicas de todas las Ciencias; paganas como cristianas, de la humanidad entera.

Aquí se encuentra el pensamiento del hijo de las selvas que lo vieron nacer, se crió y se educó debajo de ellas como se educan las aves para cantar, y se preparan los polluelos batiendo sus plumas para volar desafiando el infinito para mañana cruzarlo y con una extraordinaria inteligencia muestran entre sí el semblante de amoroso cariño para tornar el vuelo, el macho y la hembra, para hacer uso de la sabiduría que la misma Naturaleza nos ha enseñado, porque ahí en ese bosque solitario se encuentra el Libro de los Amores, el libro de la Filosofía; porque ahí está la verdadera poesía, la verdadera filosofía, la verdadera Literatura, porque ahí la Naturaleza tiene un coro de cantos y son interminables, un coro de filósofos que todos los días cambian de pensamientos; pero nunca saltan las murallas donde está colocado el Ministerio de las leyes sagradas de la Naturaleza humana la que está subordinada por la Naturaleza Divina y también todas las noches; y ese coro de hombres no indígenas que han corrido a conocer los grandes claustros de enseñanza en los Colegios, en las Universidades principiando por las escuelas primarias, etc.; no han podido ni podrán conferenciar acerca con ese libro de la Poesía, con ese libro de la filosofía que tiene tres poderosos reinos, y que no los han podido conocer aquellos niños de la antigüedad, los de la Edad Media, ni los de la presente; aquellos que se mecieron dentro de las cunas de oro y otros dentro de las cunas de cristal; pero ese niño que nació en un Portal en una Cuna de paja, se meció como el pájaro en su 
nido tejidos de pajas, fojió todo el libro de la Poesía, todo el libro de la filosofía y todo el libro de la Literatura, libros que los había estudiado desde la Eternidad; él sabía dónde está oculto el jardín que creó Dios al principio del mundo para colocar al primer hombre y a la primera mujer; jardín que está oculto de la vista y de la idea de esos grandes hombres que se han chamuscado las pestañas estudiando y que pasmados hoy están tendidos en la eternidad; el guerrero con su espada, el Poderoso con su cetro y el Sabio con su pluma; y mañana, yo con mi interpretación.

El Aguila de la interpretación del indiecito va acompañada de un concierto de palomas pero no de la paloma que cucurrutea sino de la paloma que se queja en el bosque sobre el pardo copo de Laurel, concierto que vigila ese Gigante en su Palacio, Palacio de mi pensamiento. Ese idilio que él mismo canta, el mismo florece, el mismo se perfuma, el mismo renace, el mismo se cultiva, el mismo reabriga con los calores y los hielos de la misma estación de los tiempos que pasan.

Ese concierto de filósofos que tienen esos tres poderosos reinos y que forman un libro, una lógica donde se encuentran todos los teoremas fundamentales de la Ciencia del Mundo material y también la Ciencia del Mundo Espiritual; ¿dónde se encuentra la cuna de la Sabiduría? Pues la Cuna de la Sabiduría está debajo de crueles montañas escondidas, según lo dijo los sueños del indígena que subió a visitar al recién nacido que estaba en dicha Cuna de paja, que estaba hospedado en uno de los corredores de "La Casa de Belén", aquél que dejó la Piedra de la filosofía, etc., ese indígena que le llevó un regalo de oro como a hombre y Rey de los reyes.

La ciencia tiene un jardín muy extenso que pocos son los hombres que la han mirado pero de muy lejos, el indiecito le ha mirado de muy cerca unido con esos discípulos que la Naturaleza ha criado y cría en el bosque en esos momentos de la charla interminable que tienen los arroyos de las fuentes; en esos momentos que ronca el tigre, ruge el león, silba la serpiente, canta el grillo y la chicharra, gime esa paloma torcaz y cruza el bosque, es el momento del recreo que esa maestra que es la Sabiduría, ha ordenado armónicamente a sus discípulos; y después cruzan los cuatro vientos de la tierra que son los sembradores que tiene la Naturaleza, etc. ¿Qué cosa es la Naturaleza?

La naturaleza es el Libro de Dios y la Ciencia de Dios, es infinita y la Ciencia del hombre es finita, porque él aun cuando más estudia no sabe nada, porque "su corazón está lleno de orgullo y de envidia contra el pobre ignorante, etc.; el blanco odia al indígena de muerte, porque él de frente están sus labios bañados de sonrisa pero es con el fin de humillarlo, etc., etc.; digo de humillarlo, haciéndole revelar palabras para poder hacer negocios; actos y razones que los aclararé más adelante con franqueza.

Pero ese indio Quintín Lame que logró interpretar el pensamiento de la hormiga y de varios insectos que cultiva la Naturaleza humana; el pensamiento de la hormiga más pequeñuela es el mismo que tiene el cóndor cuando se está acabando de vestir en la cueva, es el mismo que tienen los hijos del tigre, y es el mismo que tiene el hijo del hombre; pues la hormiga al desenvolver el broche de sus alas sale de la guarida pero no sigue el camino conforme a las otras, pues ella se trepa sobre la arena y bate sus alas parece que desafía al infinito; porque se siente potente; pero al trazar el camino la asalta su enemigo, y así mismo asalta el error al hombre. El 
hijo del tigre hace ensayo del modo como ha de hacer presa y así ensayó el blanco contra el indígena colombiano ensayos que los ha llevado a cabo desde el día 12 de Octubre de 1492 hasta hoy 1939. Por esa raza que duerme allá en esos cementerios en el vientre de la tierra que grandes hombres de mi raza asfixiados pasaron para la Eternidad, dichos hombres indígenas hicieron su campamento para favorecerse de la cuchilla española en el centro de la tierra, y ahí permanecen hasta hoy, etcétera, etcétera.

\subsection{La virtud del indígena nacido y acariciado por la Naturaleza debajo de la madre selva}

Este capítulo se consagra únicamente a demostrar el valor de la virtud acompañada de la fé, porque la fé que no está acompañada de las buenas obras está muerta. El que teme a Dios obra bien, y el que busca la justicia la poseerá, saliéndole ella al encuentro como una madre venerable. La alimenta con pan de vida y de inteligencia y le dio al indiecito a beber del agua de la sabiduría saludable, y se estableció en ese inmenso valle que tiene tres Praderas donde están los tres jardines de "Abaná" que cultiva la naturaleza donde nacen los aires puros, los que rejuvenecieron el espíritu de varios conocimientos filosóficos de mi persona. Así nacerá mañana un concierto de indígenas de esos descendientes legítimamente de nuestra tierra Guananí, descendientes de esas tribus odiadas, perseguidas del hombre no indígena; pero la Ley de la compensación existe señores, porque ella misma es la justicia vengadora porque el hecho del viejo Adán y el capricho de la vieja Eva, al pase de cuatro mil años, se pagó.

La raza indígena aquí en Colombia ha sido odiada por todo el capitalismo, y muy pocos sacerdotes o religiosos han hablado por ella, porque han estado sus pensamientos muy lejos de las ideas del Padre Fray Bartolomé de las Casas, porque no han habido sacerdotes de nuestra propia raza que identifiquen el verdadero derecho que tenemos los indígenas de Colombia legítimamente indígenas, y no de los que por sus venas les corre ya sangre española que está manchada de envidia, egoísmo y orgullo, etc., y que sus conciencias de generación en generación vienen manchadas con sálpicos de sangre indígena.

Esa Pradera de la Ciencia es a donde está la Ley del hombre y la meditación del mismo, la Ley de unidad. Cuando en el hombre reina la paz y armonía entre la parte inferior y la superior, entre la imagen o imaginación y la inteligencia, entre las pasiones y la razón, etc., porque el entendimiento agente o luz de la razón es participación de la luz Divina, etc., etc. Le muestra al hombre de fé alta secretamente, para qué fue creado, porque ese Don de la inspiración: le hace conocer esa floresta de las tres virtudes que la primera baja a la profundidad, la segunda se extiende y la tercera se eleva y se coloca en las celdillas que tiene el infinito; parece que son tres dioses los que tiene la Naturaleza; el primero sacude su larga melena de espuma, el segundo y tercero crispan su cabellera de rayos y escribe sobre las inmensas playas del Arén mostrando su ímpetu, en medio de la oración que desencadenó ese Dios de la inspiración allá en esas praderas donde cruza el águila de la psicología contemplando el palacio donde se engendra el pensamiento del hombre, para tomar el nombre del Gigante del pensamiento del ignorante, pero soy sabio para lo bueno, é ignorante para lo malo; sin haber conocido ni divisado de muy 
lejos la escuela ni el colegio, ni que nadie me hubiera dado a conocer la letra o, letra de que hizo mención Francisco José de Caldas cuando marchó con la frente serena sobre las gradas que lo conducían al cadalso. Así muchas familias indígenas hicieron sus lóbregas poblaciones en el vientre de la tierra para librarse de la cuchilla de los malvados que corrían como lobos de rapiña sobre el pueblo indígena colombiano en 1502, 1503 y 1509. Ese crimen está oculto señores; pero esa justicia llegará, en que el indio colombiano recuperará su trono, etc., etc.

Yo no soy profeta; pero sí he sido y soy el Apóstol de mi raza, y los hombres de raza blanca que me han hecho la guerra en los Departamentos de Nariño, Cauca, Valle del Cauca Huila y Tolima ninguno se ha podido reír como dijo el señor José María Barona, "el día que saquen al indio Quintín Lame para el panóptico de Tunja, hago tres bailes, etc.".

El Doctor José Hilario Cuéllar dijo en una Vista Fiscal que sería más fácil que al unirse los dos ríos Cauca y Magdalena, volver a separar a una larga distancia las aguas, y no que el indio Quintín Lame, mi persona, separase la raza indígena de la blanca y mucho menos en la política, etc.; pero dicho magistrado o Fiscal se equivocó porque ese pensamiento cayó como el árbol que abandona la flor y la hoja, y que la hoja es juguete del viento, así se jugó la Lógica y se ha venido jugando hasta hoy. Lógica nacida propiamente de esa imagen de mi pensamiento y que ya dió a luz sobre la cuna de la civilización colombiana el día de hoy.

\subsection{La experiencia}

La experiencia tiene dos poderosos muros, el uno es visible y el otro es invisible, muros que me han servido de trincheras poderosas para favorecerme de la metralla de mi enemigo en el campo de encarnizados combates en lo material, en lo civil y en lo moral; pero para esto se necesita tener una memoria feliz y única; el primer muro es donde está depositado todas las acciones que le danzaron al hombre desde el momento en que tuvo uso de razón, como el indígena que nunca se olvida del blanco que le pagó a su padre de obra y lo ultrajó de palabra, a su hermano, a su esposa; él no dice nada, pero en el interior conserva el pensamiento del gallo de pelea y se venga

haciéndole salir una úlcera en que dicen en su lenguaje algunas personas maleficio. El blanco le roba la finca, al indígena, emborrachándolo; haciéndole firmar documentos de débito sin deberle; llevándolo ante los jueces para seguirle la ejecución, y el juez se presta diciéndole a uno: "es mejor que le pague"; contradice úno, "pero yo qué le pago si no le debo nada"; le ordenan al indio: "nombre abogado". El indio nombra su abogado pero el hurtador, ladrón o estafador se une con el abogado del indio que desea defender su derecho o propiedad, o semoviente, etc., y lo requiere diciéndole "partimos el dinero que estoy ganando y dame el pleito ganado, porque entre los blancos o mestizos tenemos que favorecernos, el indio ¡eso qué!" etc.

El segundo muro de la experiencia, es decir el hombre lo que sabe y saber decirlo cuando es tiempo y sazón, porque más seguro es callar que hablar; pues la llaga que está cubierta nunca es pisada de la mosca y cicatriza pronto; el caudillo, defensor o jefe indígena consulta interiormente o exteriormente por medio del corazón 
de María concebida sin pecado, corazón donde vive y reina el Misterio de La Trinidad, porque es la cuna de la Sabiduría [...]

En el murmullo lejano, por medio de una fe viva acompañada de buenas obras, allá en los mares, en el susurrar de los vientos sobre el ramaje de los viejos robles, en los desiertos donde la soledad no habla; se cruza de repente dentro del interior del indiecito y le hace oír la palabra de la Majestad del que hizo al hombre de la nada, y que lo hizo a su imagen y semejanza y le dice así: "Oíd las palabras de Dios en los montes en todo este desierto que cruzan en medio de las brisas del perfume leve que lleva de la silvestre flor; mirad su sombra entre las aguas que magníficamente se mueven; mirad su sombra en medio de la inmensidad que nos cubre; me dijo: tu nombre está escrito en el Libro de los predestinados del Señor; por medio de tu fe Dios te ha dado la vida, dentro de tu cuita y tu faena Dios te ha consolado en los delirios, delirios que no han podido escribir hasta hoy los cuerpos celestes porque una cifra misteriosa marchó en tu corazón; cifra que jamás la consiguieron los sabios en cuarenta años de estudio, etc.”, yo estudié la Ontología en el bosque y conocí también sus atributos inmediatos quien investigaba todas las razones supremas de Dios, del hombre y del mundo, el alma humana y Dios eran los tres seres cuya existencia deseaba yo descubrir, apoyado en una fe muy alta; por eso mi conducta hasta hoy no ha sido tachada, por las más célebres inteligencias que escribieron la filosofía pagana y después escribieron la filosofía cristiana, ni tampoco por ninguno de los historiadores y jurisconsultos de la presente edad.

\subsection{La sesión jurídica}

La sesión jurídica de este Capítulo debo demostrar con franqueza al pueblo indígena colombiano que hoy están sus deberes y derechos, como también sus dominios mordidos y engangrenada la mordedura por la serpiente de la ignorancia y la ineptitud o analfabetismo; pero el indígena que interprete el pensamiento de los seis Capítulos de esta obra se levantará con la facilidad más exacta para hacerle frente al "Coloso de Colombia" y reconquistar sus dominios en la forma que yo reconquisté los Resguardos de Indígenas de Ortega y parte del Chaparral en el Departamento del Tolima. Mi reconquista principió en el mes de Abril del año de 1922 y terminó el 31 de Diciembre de 1938 y entré como Gobernador oficialmente a defender mis dominios conquistados en el año de 1939 unido con el Cabildo que fue compuesto de doce hombres indígenas, triunfo que hice con mi pluma y mi actitud, pensando en todo, que en la demora estaba el peligro y así ordené a esos doce hombres, para su buen Gobierno y que ese Gobierno diera ejemplo de Gobierno para el mañana. Como también el padre de familia indígena que le nazca un niño dotado de inteligencia debe conseguir la presente obra, para que le sirva a ese joven de espejo que nunca se le enveta en medio de las pirámides de hielo y de calor producidas por las aves de rapiña de nuestros enemigos las que no prevalecerán, si ese joven o jóvenes descansan sus ideologías en Dios por medio de la fé, porque la Ciencia acompañada de la fé descansa en Dios ordenador del Universo y de la ley natural

Yo he sido y soy el hombre que me siento con orgullo hoy en medio de mi raza y en medio de mis enemigos los que se burlaron de mí, los que me calumniaron, los que me pusieron nombres; las autoridades que me martirizaron amarrándome del 
cuello y de los brazos como a un ladrón y asesino facineroso, como hizo el doctor Álvarez Guzmán siendo Alcalde de Ortega, para hacerse célebre en su alcaldía y entre los suyos; clavó un botalón en la puerta del calabozo de la cárcel de Ortega y ordenó se me amarrara ahí del cuello, los brazos y la cintura en que quedé sin movimiento y me mantuvo tres días y tres noches, y ordenó no me pasaran alimentos durante los tres días, abrió la puerta del calabozo y ordenó al pueblo de Ortega subieran al balcón hombres y mujeres a mirarme como estaba castigado, y que él sabía castigar al indio Quintín Lame, ahí apareció la grandeza, ahí apareció el valiente Álvarez Guzmán con su nombre y valor inmortalizado en las páginas de la historia de Nerón.

Nosotros los indígenas debemos abandonar y despreciar la dádiva del blanco, el pedantesco palabrerío "de yo te quiero como de mi casa, como verdadero amigo y por el cariño que te tengo es que te pido rebaja de lo que me vendes", etc., etc.

El abogado blanco dice, "ese pleito está muy trabajoso, pero si me pagas ochocientos pesos $(\$ 800)$ dándome en este momento la mitad, de aquí a ocho días está tu pleito ganado". El indígena contesta; "le traigo doscientos pesos (\$200)". Contesta el blanco "no, no, si me das los cuatro". Contesta el indígena, "dentro de quince días se los traigo". Contesta el blanco "no, tráigamelos dentro de ocho días", y le ofrece y le asegura que el pleito yo lo gano". Cuenta el indígena los cuatrocientos pesos, se pasan dos meses y le pregunta el indígena, “¿Cómo va el pleito señor abogado?". Contesta el haragán y mentiroso, "he hecho todo lo posible, ya casi tengo el asunto por cuenta mía; pero hoy que estoy limpio, dáme cien pesos que te los agradezco como si me los regalaras". El indio dice, "hoy no los tengo, pero de aquí a ocho días se los traigo aun cuando sean cincuenta". A los cinco meses de no saber el indígena le pregunta al Secretario del Despacho, y contesta. "Hacen dos meses que presentó su abogado un memorial y no ha vuelto", pero si él me dijo que tenía el pleito ganado ya"! Contesta el Secretario, "ese señor lo está es engañando, busque un abogado bueno, honrado y que vaya al despacho"; pero ya el dinero que tenía el indígena lo acabó, quedó en la miseria y el pleito se lo ganó la contraparte.

El defensor del pobre indígena se queda muy contento, porque estaba de acuerdo con el abogado de la contraparte. Por eso en casa del abogado está el hambre, está la miseria, la ruina; pero del abogado que no tiene conciencia y muere en la ruina como murió Cristóbal Colón en la ciudad de Valladolid.

Poderosas razones que me llevaron a mí a interpretar la Ciencia de la Criminología y el Derecho Civil, y esas Ciencias fueron apoyadas por medio de la fé ante el Juez Supremo dueño de todas las conciencias humanas, porque fué el primer Magistrado que adivinó el pensamiento del Jefe de Las Milicias Eternas quien pensó en rebelarse en contra de su misericordia infinita.

Dicho Juez Supremo pronunció la segunda sentencia en la tierra dentro de sus cultivos que él había sembrado y ahí había colocado el mayordomo o cuidandero acompañado de una mujer y que el tocador de ésta era el lago que regaba dicha sementera, y el hortelano se complacía con mirar la belleza de las flores y los frutos; lugar donde se cometió el segundo pecado y que muchos historiadores dicen que fue la serpiente que regaló una manzana, etc., lo cual no fue así; fueron las leyes de la naturaleza humana la que ordenó el estricto cumplimiento de sus leyes, pues el reino animal nos muestra ese cumplimiento con una exactitud comprensible 
que los filósofos llaman Lógica y psicología porque ellos dicen haber estudiado, y yo porque lo he interpretado por los diversos seres vivientes que he mirado.

El primer hombre y la primera mujer fueron notificados personalmente por ese Juez Supremo la sentencia de destierro, porque Él mismo lo había determinado así, porque el que crió el hombre a su imagen y semejanza lo dotó también de conocimientos y por eso hizo aparecer su divinidad en una de las hijas de Israel con el nombre de "María Concebida sin pecado la que ruega a ese Juez por nosotros los que con fé muy alta recurrimos a ella".

Aquí desarrolla el filósofo Cristiano su ideología para mostrar a la humanidad que sí es filósofo y que para poderse remontar hizo hincapié en la piedra de la filosofía, porque hoy mi obra será tildada por muchos hombres miopes de pensamiento y faltos de la compañía de la imaginación del hombre la que conocí allá cuando estaba apegado en un botalón saciando la sabiduría de Álvarez Guzmán, Alcalde de Ortega en el año de 1931; ahora qué diré de los episodios que ejecutó en el Cauca el doctor Miguel Arroyo Díez unido con el doctor Guillermo Valencia y muchos otros pensadores en contra del indígena Manuel Quintín Lame mi persona, para humillarlo y poderlo condenar a mansalva y sobreseguro fuera de la Ley y la Constitución Nacional; pero ese Juez Supremo de que he venido hablando en este Capítulo es la fuente que nunca deja de correr, nunca deja de iluminar la humanidad, porque esa ley que tiene la naturaleza fue nivelada por Dios, quien hizo de la nada al universo y ese reloj que está fijo en el infinito y que ningún platero o mentiroso que hay en el mundo han podido cortarle o perturbarle una pieza a ese reloj que edificó el mecánico que vive allá en el Palacio de la inmortalidad, donde existe la realidad, realidad que conoce el alma del hombre que ha vivido bien.

La jurisprudencia que yo aprendí fue enseñada allá en esos campos de lucha donde me acompañaba esa imagen que iba alzando el vuelo de imagen en imagen, y yo la miraba hoy más bella que ayer e imaginé, que mañana sería más bella que hoy, y que la sabiduría del hombre debía ser más exacta para coger las flores de la Ciencia dentro de ese jardín que cultivó el primer hombre y la primera mujer; jardín que sembró ese Juez Supremo que reina en el Palacio de la inmortalidad, ya antes citada porque el día de mañana el hombre será más sabio que ayer y mañana será más sabio que hoy.

Señores indígenas, son tres elementos de prueba: El primero es la confesión; el segundo declaración de testigos, y tercero documentos; pero no vas Vos a confesar el hecho porque confesión de boca, satisfacción de obra; la defensa está en vuestros labios, y ahí mismo está la condena; el hombre nunca debe confesar sus hechos ante ninguna autoridad civil o investigador criminal; hay muchos investigadores en la Criminología que amenaza al ignorante con torturas, con calabozo, con destierro, con condenas de veinte años, etc., etc.

El hombre que se deja sugestionar de un investigador, de un Juez civil no debe existir en Colombia. Hay muchos jueces e investigadores que dicen, no niegue, no niegue, porque hay declaraciones que dicen, usted fue el del hecho o hechos, por hacerse célebres con un procedimiento que está fuera de la Ley, la razón y la Justicia.

Justicia significa el derecho que tiene cada hombre y por eso se llama "Conmutativa, distributiva y legal”. Lo mismo que el hombre que tiene resolución de cometer un delito y revela esa resolución. Tales actos son elementos materiales del delito 
donde el defensor el día de mañana no podrá defender al sindicado, ni el mismo sindicado podrá contradecirse mientras que no pruebe que estaba en estado de enajenación mental. El hombre constituye un criterio recto que le hace ver las realidades con la nitidez de la verdad y en su voluntad el perfecto dechado de la pulcritud y de la honradez que ha de dirigir todos sus actos para la Justicia y entrar a ese recinto del más elevado ministerio de la vida y dirigir los destinos humanos.

El indio es aborrecido del blanco, es odiado de muerte cuando le va a tildar y le tilda sus actos, el indio no puede ir en compañía del blanco a un café, a un hotel, a una mesa de convite, por arreglado que esté vestido, el blanco se rebaja ante los suyos, es mirado de los suyos con soberbia, etc., etc. Mucho más cuando el indígena ha penetrado el jardín de la Ciencia y el blanco queda por fuera sin poderlo penetrar, hechos que me constan cuando yo bajé de las montañas donde había divisado las Praderas de la Ciencia e interpreté lo elevada, profunda y extensa que es la Ciencia de la Filosofía; pero no quiero citar ese poderoso ramaje que tiene el árbol principal de la Ciencia, ya antes citada, porque los filósofos dicen que la Ciencia tiene una llave pero yo no la conozco; pero sí la puedo interpretar en caso de seguridad. El indígena colombiano debe tener su representación, primero en el Senado de la República y en la Cámara baja, en las Asambleas departamentales y en los Concejos Municipales por las razones siguientes:

a) Porque el Legislador da órdenes contrarias, dicta leyes contrarias contra la propiedad comunal de nosotros los indígenas por nuestra ignorancia;

b) El Legislador ordena que repartamos nuestros terrenos de Resguardos, pero no dice que el blanco que tiene sus latifundios también los repartan; porque así como se ordena por medio de leyes, a una raza débil reparta lo suyo, también debe ordenarse a una raza fuerte por su inteligencia y astucia, y

c) Es el medio más apropiado que debe tener nuestra raza proscrita y abandonada por la Civilización Colombiana.

$$
* * *
$$

\section{La bola que rodó en el desierto}

Esa bola que rodó y pasó por en medio del ganado feroz que tiene la naturaleza en el desierto debajo de ásperas montañas rompió el tanque de veneno mental de la Corte Suprema de Justicia, Sala de Casación Criminal Colombiana. Era el indígena que había descubierto las creaciones titánicas de sus antepasados que vivieron en palacios, y desafiaron a los siglos. Pero yo era un perro que estaba encadenado por mis verdugos esbirros, y que ladraba pero no podía morder en la casa de la injusticia, ciudad de Popayán, capital del Cauca.

\subsection{El contrabando antijurídico}

A mí se me sindicó de siete (7) delitos: homicidio, no pago de impuestos, etc. Pero subí las gradas a sentarme al "banco" de los acusados, no como la ovejita que sube al matadero y da su trémulo balido. Yo dí el grito: aquí está sentado el inocente Abel y en ese momento una voz interior me indicó cómo había de destruir las mu- 
rallas de la falsedad construidas por los hombres que juraron falsamente ante Dios y que después intentaron quitarme la vida material a bala, pero no les sirvió el arma, después nombraron una comisión de tres hombres nacidos y criados en Ortega Tolima ; pero fueron tres cobardes que en su nombre llamaron a la señora Saturia Bonilla, la esposa mía, dándole un machete para que me descogotara quitándome la cabeza, recibiendo la suma de cinco mil (5.000) pesos oro que los dió el oligarca rico archimillonario Bernardo Lozano Bahamón, unido con los perjuros descendientes de los que llegaron el día 12 de Octubre de 1492.

Los grandes hombres que llegaron el día 12 de Octubre de 1492 y se apoderaron de nuestra propiedad inamovible eran unos rateros que estaban pagando sus hechos en las cárceles o castillos de España, y por Decreto ordenó el Rey de España que vinieran a pagar el resto de su condena en el destierro. El monarca los mandó fué a servir a Reyes indígenas y vinieron fué a matar y a asesinar a todos los Reyes Indígenas.

Llevamos más de quinientos años de sufrimiento en medio del hambre, de la tristeza, de la persecución del blanco a la propiedad indígena, porque desde el 12 de Octubre de 1492, quedó perseguida la cultivación agrícola industrial de nuestra Raza Indígena. Pero aquella "Bola" que recusó los Tribunales rompió el tanque del veneno mental, comenzando por romper la acción Jurídica del Poder Judicial. Hoy hago resonar en mi obra el pensamiento indígena, porque así tenía que aparecer en medio de la calumnia, del robo, del hurto, del engaño, de la documenta falsa. Al principio se abrieron por mí Escuelas Indígenas en las veredas de Ortega, pero luego estas fueron incendiadas por los blancos. El Personero José Galvis, el Alcalde Alvaro Guzmán, la Policía de Ortega, todos estuvieron a orden de los ladrones : Alcaldes, Jueces Municipales, Jueces ordinarios, el Tribunal del Trabajo, el Tribunal del Poder Judicial y la Gobernación del Tolima. Yo apelé ante la Corte Suprema de Justicia Sala de Casación Criminal Colombiana, pero esta malvada Corte Colombiana Sala de Casación Criminal amparó 23 delitos Criminales: $1^{\circ}$. Denegación de Justicia al Cabildo de Indígenas de la Tribu de los Grandes Resguardos de Ortega y parte del Chaparral Departamento del Tolima. $2^{\circ}$. Delito de Concusión. $3^{\circ}$. Abuso de autoridad, y usurpación de funciones públicas. $4^{\circ}$. Delitos de los abogados o apoderados contra los indígenas y falsedad de Documentos. $5^{\circ}$. Delitos contra nuestra Economía Industria y Comercio. $6^{\circ}$. Delito contra el sufragio y Libertad, etc.

El señor Alvarez Guzmán Alcalde Municipal de Ortega dió órdenes que me quemaran las tres casas grandes del caserío de Llanogrande. Una era Escuela de varones otra era Escuela de niñas. Esto sucedió después de un violento ataque y abaleo que hicieron contra mi persona siendo víctimas de muerte algunos indígenas de los asaltos y atropellamientos cometidos por los partidos politiqueros Liberales y Conservadores tradicionales, contra la Raza de Huestes indígenas de la tierra Guananí.

Esa negativa de permitir la educación de la Raza Indígena, condenada a permanecer en el analfabetismo y la ignorancia, para que tuvieran que arrodillarse los indios para saludar a un blanco.

Yo soy el indígena que fué educado en las selvas por medio de la "Voz del Silencio", allá en la casa del tesoro de los humildes donde me eduqué para la defensa del indiecito ante las calumnias de mis enemigos blancos unidos con los Jueces, 
Magistrados y Ministros Colombianos, los que cruzaron el dedo y juraron falsamente ante Dios, para luego negarle a la Tribu Indígena la educación, la justicia y la verdad. Los indígenas fueron encarcelados en las celdas de los Panópticos, en los calabozos de las cárceles colombianas. Allí gritó la justicia y la verdad durante quinientos años o algo más. Pero una sombra se educaba y se educó, cuando "la Voz del Silencio" penetró todo mi cuerpo de un raro calor y de valor Jurídico para presentarme ante el Tribunal de la Soberanía Nacional Colombiana que es el Honorable Senado de la República y denunciar la Corte Suprema de Justicia Sala de Casación Criminal Colombiana. Pero hasta hoy Primero de Mayo de 1963 no se ha nombrado nueva Corte y continúa el contrabando antijurídico contra la Raza Indígena Colombiana, porque el Ejecutivo Nacional Colombiano, no ha vuelto una mirada de amparo en defensa de nosotros los indios que estamos sometidos a la esclavitud por los ricos oligarcas unidos con los Jueces de Investigación Criminal, los Jueces Municipales, los Jueces ordinarios, los Jueces Superiores y Tribunales.

Los Jueces de Investigación Criminal nombrados por el señor Ministro de Agricultura y Comercio... Sección Resguardos violaron muy triste y lastimosamente la Ley 81 de 1958, firmada por el Honorable Senado, y no fueron Jueces ilustrados para defender los intereses de los indios, sino que abusando de nuestra ignorancia se aliaron con los ladrones, y nos gritaron públicamente que cuidado con irlos a denunciar por estos hechos.

Nosotros los denunciamos, pero el Primer Magistrado Doctor Guillermo León Valencia aceptó los crímenes, los asaltos, los incendios, el injusto cobro ilegal de los impuestos violando los artículos 155 y 156 del Código Penal. Pero este indígena que recibió educación debajo de las sombras de ásperas montañas, dirigió una carta al señor abogado y defensor de la Soberanía Nacional que es el Honorable Senado Colombiano, invitándolo a que diéramos el grito a pulmón abierto: "Viva la defensa de la verdad y la Justicia en Colombia". Pero hasta hoy 1o. de Mayo de 1963 no me ha contestado.

Los señores que llegaron el 12 de Octubre de 1492 eran una cuadrilla que asaltó nuestra tierra Guananí cultivada de distintas agriculturas. Y sus descendientes son los Jueces que mandó el Gobierno Nacional a investigar los hechos causados contra la Tribu Indígena del Resguardo Nacional de Ortega y Chaparral Departamento del Tolima. Y así sucesivamente ha sucedido en todo el territorio de la "Tierra Guananí", hoy con el nombre de Colombia. No hay seguridad, porque aún la Corte Suprema de Justicia no es Corte defensora de la verdad y de la Justicia para nosotros los indios sino una Corte que amparó 23 delitos los que subieron por apelación contra dos Tribunales, el del Trabajo, el Judicial y la Gobernación del Tolima. La Corte violó triste y lastimosamente el artículo 60 del Código Judicial y siendo la Corte un Juez de investigación Criminal está haciendo parte de los Conquistadores rateros, salteadores, ladrones, incendarios, denegadores de la verdad y de la Justicia a la Raza Indígena de la Tierra Guananí, hoy Colombia. La Corte Suprema de Justicia es la verdadera responsable porque los Magistrados son compañeros, nietos, biznietos, tataranietos de todos esos "conquistadores" que estaban pagando sus hechos criminales en los calabozos dentro de los Castillos de España.

Los hombres de raza cobriza ó blanca descendientes de los rateros y ladrones de ayer han amontonado y están amontonando todos los hechos que los llevará de cabestro a la desgracia, como fueron llevados a la prisión los seguidores de Napo- 
león Bonaparte, así serán terminadas todas las infamias de los que llegaron el 12 de Octubre de 1492 a nuestra "Tierra Guananí", porque Dios tarda pero no olvida.

Yo presenté denuncio formalmente el señor Procurador General de la Nación. Presenté también denuncio formal al señor Ministro de Justicia. Presenté denuncio formal al señor Presidente del Tribunal Superior de Justicia de Ibagué, Tolima. Todos estos denuncios fueron perdida de trabajos y de papel.

\subsection{La civilización montés}

Esa Bola que he mencionado al principio rompió el tanque donde estaba depositado el veneno mental de todos esos hombres que llegaron y se apoderaron de todos los derechos inamovibles que tienen los objetivos del suelo y los objetivos del subsuelo de toda nuestra propiedad de la Tierra Guananí.

La nación de hombres civilizados negaron el asesinato que intentaron contra mi persona, el abaleo, el envenenamiento a mi persona, los sufrimientos de los severos castigos dentro de los calabozos y Panóptico de Popayán y de Ibagué encadenado con una barra de grillos de peso de 28 Libras. En los calabozos de Popayán duré un año incomunicado. Los blancos de Popayán preguntaban ¿cuándo se morirá el indio Quintín Lame?

El que había pedido la pena de muerte fué el Padre del actual Presidente de la República Doctor Guillermo León Valencia. No quiero expresar todas las órdenes que quiso darme el que escribió "Anarcos" porque le perdoné todos los graves hechos contra mi persona. Pero por ser el poeta enemigo de los indios, yo no le perdoné cuando expiraba para pasar de esta vida a la otra.

A mí me fue negada la educación por el Doctor Miguel Campos Cárdenas porque amenazó severamente castigar a mi Padre Mariano Lame razón para que mi padre me diera una dunda de cáscara de ganado cuando le pedí que me mandara a estudiar a la escuela, porque había conseguido posada en la casa del señor José Alvino Mosquera y alimentación como hijo obediente. Después de darme la dúnda tomé la cuesta y pensé que a las cuatro de la tarde balaba de la montaña con el atadero, pero llegué y entré a la montaña y perdí completamente el sentido pues en vez de devolverme continué buscando la vía para devolverme porque ya había cogido el atadero. Se anocheció y busqué un árbol para dormir en las celdas o bambas de la cumbre porque sentí movimiento de animales feroces.

Al segundo día me combatía el hambre pero encontré muchas frutas de árboles silvestres maduras. A eso de las diez de la mañana pasaron recogiendo los dueños de las frutas que eran tres osos reales pero me sintieron y rodearon el árbol donde yo estaba trepado en la copa, y uno de ellos se preparó en dos patas, y yo me preparé con el machete en mano para quitarle la cabeza, porque valor si tenía y ese valor si lo tengo hasta hoy. No es valor jurídico, ni valor civil, sino que es un valor montés. En el árbol se me presentaron tres niñas que me miraron bañados sus labios de sonrisas y me hablaron así: Señor esta es la casa del Tesoro de los Humildes. Dijo una "yo soy la virtud". Habló la segunda y dijo "yo soy el bien unido con la virtud". Habló la tercera y dijo "yo soy tu esperanza venturosa; porque una ventura te ha traído a esta casa porque es el Templo del Tesoro de los Humildes y de la virtud ante todos los hombres de civilización. 
Por eso la civilización mía es montés. Razón para haberle pedido al defensor de la Soberanía Nacional Colombiana que es el Senado de la República en una carta que yo le dirigí como abogado que recibí mi educación debajo de las selvas, al doctor abogado que había recibido su educación en las universidades blancas para que diéramos un grito en defensa de la verdad y de la Justicia a fin de que fuera conmutativa distributiva y legal en Colombia, en defensa de los esclavos indígenas absolutos dueños y señores de la Tierra Guananí, hoy con el nombre de Colombia.

Yo me referí a una frase que explicó Doña Esmeralda Arboleda, señora Payanés.

Pero el señor doctor abogado de la Soberanía Nacional de Colombia negó la contestación a la carta del indígena hasta hoy. Pero yo como defensor que recuso la Corte Suprema de Justicia Sala de Casación Criminal debo mostrar con ese valor montés, que recibí mi educación en la Universidad montés allá en los bosques solitarios y sombríos que creó la naturaleza y los ganados feroces. Y esa Bola a que me vengo refiriendo cruzó rodando por medio de dicho ganado montés, y en vez de tomarla en sus largos colmillos se asustaron y le abrieron campo. Esa Bola rodante era yo el indígena Manuel Quintín Lame. 